\title{
A Novel fuzzy Control Strategy for Maximum Power Point Tracking of Wind Energy Conversion System
}

\author{
Moez Allouche **, Sahbi Abderrahim *, Habib Ben Zina*, Mohamed Chaabane* \\ * Laboratory of Sciences and Techniques of Automatic Control \& Computer Engineering (Lab-STA), National Engineering \\ School of Sfax, Tunisia \\ (moez_allouche@yahoo.fr, abderrahimsahbi@yahoo.com, habibbenzina@yahoo.fr, chaabane.ucpi@gmail.com)
}

${ }^{\ddagger}$ Corresponding Author; Moez Allouche, National Engineering School of Sfax, B.P.W 3038 Tunisia.

Received: 17/06/2019 Accepted: 03/08/2019

\begin{abstract}
This paper presents a novel fuzzy control strategy for maximum power tracking of Wind Energy Conversion System (WECS) using a Permanent Magnet Synchronous Generator (PMSG) supplying a DC load through a AC/DC converter. The proposed fuzzy controller allows to extract the maximum power from the wind turbine which leads to an optimal operation of the WECS. First, the dynamics behaviour of the (WECS) is represented by a Takagi Sugeno (T-S) fuzzy model. Then, a reference model-based tracking controller is proposed to achieve a maximum power point tracking even when we consider varying wind speed profile. The controller gains are calculated by solving Linear Matrix Inequalities (LMIs). Finally, simulation results are presented to illustrate the effectiveness of the proposed approach.
\end{abstract}

Keywords T-S fuzzy model, Wind conversion system, Linear Matrix Inequality.

\section{Introduction}

Renewable energies, derived from the sun, the wind or the sea, have long been considered as alternative sources to the energy problems of our civilization, offering the advantage of being unlimited and non-polluting, but not always available at low prices. Currently, several solutions are proposed to reduce this cost, such as the use of advanced control laws, which allow to improve significantly the performance of the wind turbine operating at variable speed. The implemented control algorithms aim to optimize the energy captured by the wind turbine, and then to increase the global efficiency of the Wind Energy Conversion System [1]. The operation of the wind turbine is divided into several distinct zones, which depends on on the speed of the wind acting on its rotor: for low speeds, the main objective is to maximize the energy generated by the turbine, the power is proportional to the cube of the wind speed while for high wind speeds, the electrical power produced must be limited and regulated to the rated generator power [2]. The wind energy produced by the turbine depends strongly on the wind speed profile. The control system continuously adjusts the rotor speed function of the wind speed level, thanks to the use of AC/DC converter which allows to operate at the maximum power zone. Thus, the problem of wind turbine control is converted as multiobjective tracking control of a multivariable system, nonlinear and strongly dependent on a stochastic input represented by the wind speed

To solve these problems, many strategies have been proposed, among them, we can quote the use of PI controllers with a fixed gains [3], or controllers designed from the fuzzy logic approach $[4,5,6]$. Other optimal control law has been developed from a linearized model over different operation zone, such as the LQG control [7, 8, 9] or the robust control which minimizing a $\mathrm{H} \infty$ criterion $[10,11$, 12]

Currently, TS approach is considered as a very useful tool for modeling non-linear systems, being based on the decomposition of the dynamic behavior of the system into several operating zones, each characterized by a sub-model of reduced complexity $[13,14,15,16,17]$. In this context, several works have been proposed to solve the problem of maximum power point tracking control applied to the wind turbine system [18, 19, 20, 21, 22, 23].

In this paper, we present a reference Model-Based Tracking Control of (WECS) to improve energy conversion and reduce the disturbance effect due to rapidly-changing of wind speed by using an $\mathrm{H} \infty$ performance. This controller is designed by using a collection of linear local models blended together with weighting functions. For each model defined around an operation zone, an optimal controller minimizing a 
$\mathrm{H} \infty$ criterion and taking into account the properties stochastic of the wind speed is designed. The fuzzy controller applied to the system is then obtained by interpolation of each local controller. The proposed fuzzy control law assures:

- a fast convergence speed of the wind turbine power to the maximum power point (MPP).

- a smoother response in steady state without oscillation around the MPP.

- achieve disturbance/uncertainty attenuation

\section{Modeling of wind system components}

Figure 1 shows the structure of the wind energy conversion chain. It's composed of a fixed-pitch turbine coupled to a PMSG generator via a gearbox that transmit the mechanical power from the rotor side, running at low speeds to the generator side, running at higher speeds. The meaning of each sub-model is described in detail in the following sections.

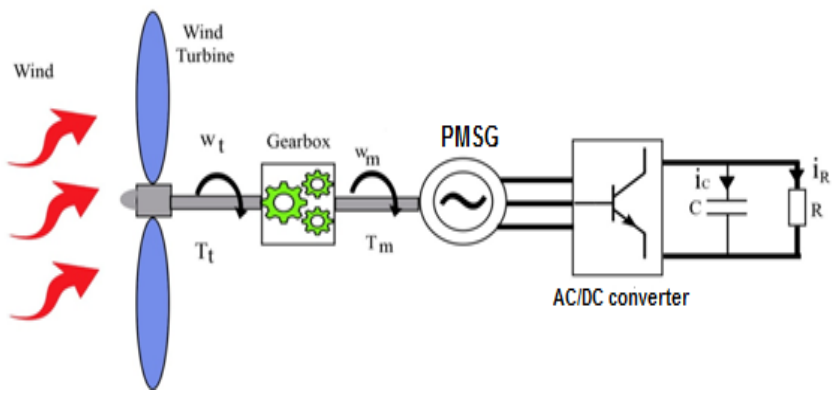

Fig. 1. Structural scheme of the wind energy conversion system

\subsection{Wind Turbine Modeling}

The mechanical power developed by the turbine shaft can be calculated as a function of wind speed, as follows [24, 25]:

$P_{t}=\frac{1}{2} C_{p}(\lambda, \beta) \rho \pi R^{2} V_{w}^{3}$

Where $\rho$ is the air density, $\mathrm{R}$ is the blade length, $V_{w}$ is the wind speed and $C_{p}(\lambda, \beta)$ is the power coefficient which depend of the pitch angle and the tip-speed ratio $\lambda$, it's a nonlinear function characterized by the following equation:

$C_{p}(\lambda, \beta)=0.43\left[\frac{151}{\lambda_{i}}-0.58 \beta-0.002 \beta^{2.14}-13.2\right] \exp \left(\frac{-18.41}{\lambda_{i}}\right)$

$\lambda_{i}=\left(\frac{1}{\lambda-0.02 \beta}-\frac{0.003}{\beta^{3}+1}\right)^{-1}$

We define also the tip-speed ratio as the tangential speed at the end of the rotor blades:

$\lambda=\frac{\omega_{t} R}{V_{w}}$

Figure 2 shows the power coefficient curve characteristic related to the tip speed ratio.

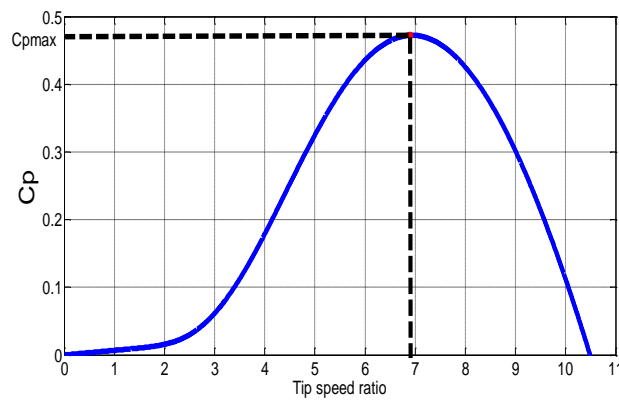

Fig. 2. turbine power coefficient versus Tip speed ration where $\beta=0$

Clearly, there is an optimal speed ratio which provides a maximum power coefficient and then ensure an optimum operation of the (WECS).

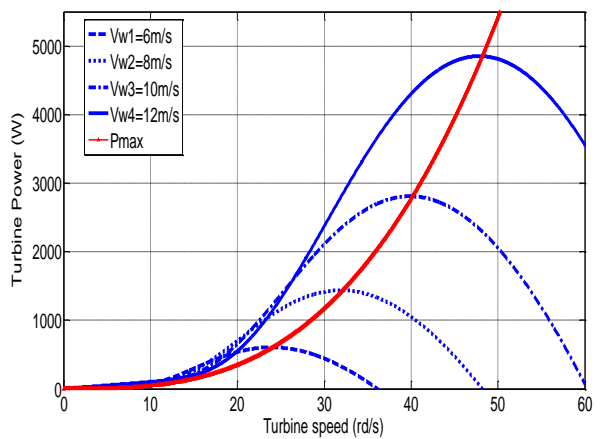

Fig. 3. turbine power versus turbine speed for different wind speeds

To formulate the optimization problem of the WECS, the turbine power characteristic with respect to the shaft speed, for different wind speed values, is considered. As a shown in Fig. 3, we notice that for each wind speed value, there is a maximum mechanical power captured by the wind turbine. Thus, if the (WECS) system operates at the optimal trajectory, the turbine torque developed at the generator shaft is expressed with the square of the rotor speed $\omega_{m}$ as follows:

$T_{t}=K_{o p t} \omega_{m}^{2}$

Where

$K_{o p t}=0.5 \pi \rho C_{p_{\max }}\left(\frac{R^{5}}{\lambda_{o p t}^{3}}\right)$

\subsection{Permanent magnet synchronous generator model}

In this section, the optimization problem of the wind energy conversion system is considered for a PMSG generator coupled to a DC load as shown in figure 1. By referring to Figure 1 , the generated DC current $i_{d c}$ can be expressed by the following relation:

$i_{d c}=C \frac{d u_{d c}}{d t}+\frac{u_{d c}}{R}$

where $u_{d c}$ is the DC link voltage.

The electrical power obtained in the DC link is:

$P_{r}=i_{d c} u_{d c}$ 
In addition, using the (d-q) reference frame, the electrical power delivered over the terminal of the PMSG is obtained from the terminal (d-q) currents and voltages as follows:

$P_{g}=\frac{3}{2}\left(u_{s d} i_{s d}+u_{s q} i_{s q}\right)$

Where $\left(i_{s d}, i_{s q}\right)$ and $\left(u_{s d}, u_{s q}\right)$ are the (d-q) stator currents and voltages in the (d-q) reference frame respectively. However, if we assume that the AC/DC converter is ideal and there's no switching loss power, a nonlinear differential equation for the DC link voltage can be obtain as:

$\frac{d u_{d c}}{d t}=\frac{3}{2} \frac{\left(u_{s d} i_{s d}+u_{s q} i_{s q}\right)}{2 C u_{d c}}-\frac{u_{d c}}{R_{e} C}$

On the other hand, the dynamic model of the PMSG is stated as follows:

$$
\left\{\begin{array}{l}
\frac{d}{d t} i_{s d}=-\left(\frac{R_{s}}{L_{d}}\right) i_{s d}+n_{p} \omega_{m} i_{s q}+\frac{1}{L_{d}} u_{s d} \\
\frac{d}{d t} i_{s q}=-\left(\frac{R_{s}}{L_{d}}\right) i_{s q}-n_{p} \omega_{m} i_{s d}-\left(\frac{n_{p}}{L_{d}}\right) \omega_{m} \psi_{f}+\frac{1}{L_{d}} u_{s q} \\
\frac{d}{d t} \omega_{m}=\frac{1}{J}\left(K_{o p t} \omega_{m}^{2}-\frac{3}{2} n_{p} i_{s q} \psi_{f}\right)
\end{array}\right.
$$

where $J$ is the total moment inertia (wind turbine and generator), $R_{s}$ is the stator resistance, $L_{d}$ is the stator inductance in the direct axis, $n_{p}$ is the number of poles, $\psi_{f}$ is the fixed flux linked by the stator windings and $T_{e}$ is the electromagnetic torque given as follows:

$T_{e}=\frac{3}{2} n_{p}\left(i_{s q} \psi_{f}\right)$

Thus, if we take into account the dynamics of the DC link, the global model of the PMSG generator connected to the DC load is given by:

$\dot{x}(t)=f(x(t))+g(x(t)) u(t)$

Where

$f(x(t))=\left[\begin{array}{l}-\left(\frac{R_{s}}{L_{d}}\right) i_{s d}+n_{p} \omega_{m} i_{s q} \\ -\left(\frac{R_{s}}{L_{d}}\right) i_{s q}-n_{p} \omega_{m} i_{s d}-\left(\frac{n_{p}}{L_{d}}\right) \omega_{m} \psi_{f} \\ \frac{1}{J}\left(K_{o p t} \omega_{m}^{2}-\frac{3}{2} n_{p} i_{s q} \psi_{f}\right) \\ -\left(\frac{1}{R_{e} C}\right) u_{d c}\end{array}\right], g(x(t))=\left[\begin{array}{cc}\frac{1}{L_{d}} & 0 \\ 0 & \frac{1}{L_{d}} \\ 0 & 0 \\ \left(\frac{3}{2 C}\right) \frac{i_{s d}}{u_{d c}} & \left(\frac{3}{2 C}\right) \frac{i_{s q}}{u_{d c}}\end{array}\right]$

\section{Optimal-Robust reference model-based tracking control design}

The global control scheme of the proposed approach is illustrated in Fig. 4. As indicated, a TS fuzzy controller related to the tracking error $e_{r}(t)=\left(x(t)-x_{r}(t)\right)$ is included which allows to force the captured wind power to follows the optimal power curve. The proposed strategy requires the use of a reference model to specify the maximum power trajectory.

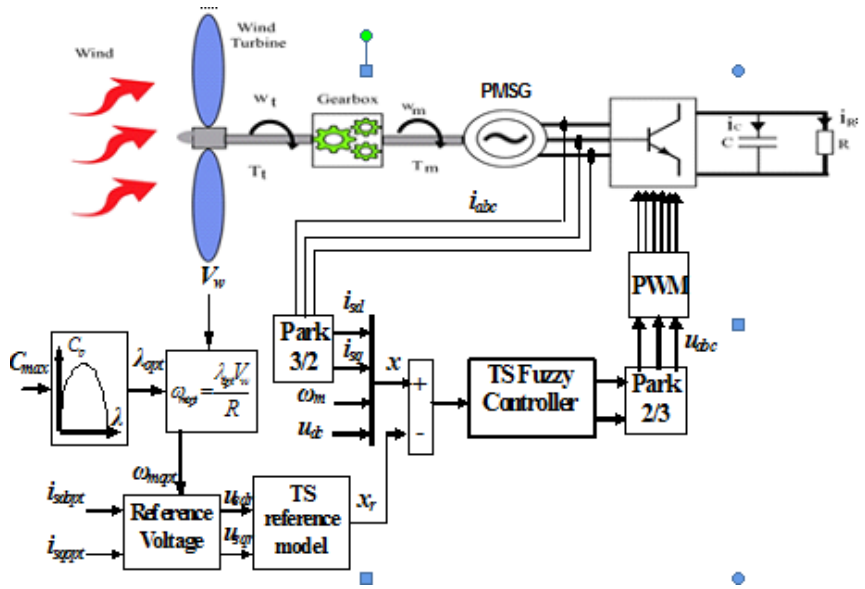

Fig. 4. turbine power versus turbine speed for different wind speeds

Before we develop the proposed fuzzy MPPT control law, the following lemma is needed to provide LMI conditions.

Lemma1: Consider two real matrices $\mathrm{M}$ and $\mathrm{N}$ with appropriate dimensions, for any positive scalar $\varepsilon$ the following inequality is verified:

$$
N^{T} M+M^{T} N \leq \varepsilon N^{T} N+\varepsilon^{-1} M^{T} M, \varepsilon>0
$$

\subsection{Takagi-Sugeno Fuzzy modelling of the (WEC) system}

Takagi-Sugeno model is a widely used tool for the modeling of non-linear systems, based on the decomposition of the dynamic behavior of the system into several operating zones, each characterized by a sub-model of reduced complexity [13]. Depending on the zone where the system evolves, the output of each sub-model contributes more or less to the approximation of the overall system behavior. The contribution of each submodel to the global model, which is a convex combination of submodels, is defined by a weighting function. The interest given to this kind of modeling is due to the fact that the stability analysis and the controller gain design associated to each sub-model can be obtained via LMI tools [14]. In this context, and according to the nonlinear dynamic system (15), we consider the sector of nonlinearities of the terms $z_{k}(t)=x_{k}(t) \in\left[z_{k \min }, z_{k \max }\right]$ of the function $f(x(t))$ and $g(x(t))$ with $k=1,2,3$ : $\left\{\begin{array}{l}z_{1}(t)=\omega_{m}(t) \\ z_{2}(t)=\left(\frac{i_{s d}}{u_{d c}}\right) \\ z_{3}(t)=\left(\frac{i_{s q}}{u_{d c}}\right)\end{array}\right.$

Thus, we can rewrite the nonlinear terms as:

$$
z_{i}(t)=F_{i \text { min }}(t) z_{i \text { max }}+F_{i \text { max }}(t) z_{i \text { min }}
$$

where

$$
\left\{\begin{array}{l}
F_{1 i}(t)=\frac{z_{i}(t)-z_{i \min }}{z_{i \max }-z_{i \min }} \\
F_{2 i}(t)=\frac{z_{i \max }-z_{i}(t)}{z_{i \max }-z_{i \min }}
\end{array}\right.
$$


The weighting functions associated for each submodel are given:

$h_{1}=F_{1 \min } F_{2 \min } F_{3 \min }$

$h_{2}=F_{1 \text { min }} F_{2 \min } F_{3 \max }$

$h_{3}=F_{1 \text { min }} F_{2 \text { max }} F_{3 \text { min }}$

$h_{4}=F_{1 \text { min }} F_{2 \max } F_{3 \max }$

$h_{5}=F_{1 \text { max }} F_{2 \text { min }} F_{3 \text { min }}$

$h_{6}=F_{1 \text { max }} F_{2 \text { min }} F_{3 \max }$

$h_{7}=F_{1 \text { max }} F_{2 \text { max }} F_{3 \text { min }}$

$h_{8}=F_{1 \max } F_{2 \max } F_{3 \min a x}$

The global fuzzy system is the weighted sum of the submodel given as:

$\dot{x}(t)=\sum_{i=1}^{8} h_{i}(z(t))\left(A_{i} x(t)+B_{i} u(t)\right)$

\subsection{Uncertain $T-S$ model representation}

Robust control design is based on an uncertainty description of the wind energy conversion system. This last, is subject to a parametric variations that can degrade its tracking performance. Hence, uncertain terms are added to the WECS dynamic model which affects the stator resistance $R_{s}$ and the inertia moment $J$ as follows:

$\left\{\begin{array}{l}R_{s}=R_{s n}+\Delta R_{s} \\ \frac{1}{J}=\frac{1}{J_{n}}+\Delta\left(\frac{1}{J}\right)\end{array}\right.$

$R_{s n}$ and $J_{n}$ are the nominal value with $\Delta R_{s}=R_{s n} \delta_{i} f_{i}(t)$ and $\Delta\left(\frac{1}{J}\right)=\left(\frac{1}{J_{n}}\right) \delta_{i} f_{i}(t) . \delta_{i}$ represents the rate variation of each parameter with respect to its nominal value and $f_{i}(t)$ is a random function. So, the uncertain T-S WECS model can be rewritten:

$\dot{x}(t)=\sum_{i=1}^{8} h_{i}(z(t))\left(\left(A_{i}+\Delta A_{i}\right) x(t)+\left(B_{i}+\Delta B_{i}\right) u(t)\right)$

the matrix $\Delta A_{i}$ and $\Delta B_{i}$ represent the parametric uncertainties with appropriate dimensions, which defined as follows:

$$
\Delta A_{i}=D_{A i} F_{i}(t) E_{A i}, \quad \Delta B_{i}=D_{B i} F_{i}(t) E_{B i}
$$

$D_{(A, B) i}$ and $E_{(A, B) i}$ are known real constant matrices of appropriate dimensions. $F_{i}(t)$ is an unknown matrix satisfy $F_{i}(t) F_{i}^{T}(t)<I$. In this case, we have:

$\Delta A_{i}=\left(\begin{array}{cccc}\delta_{i} & 0 & 0 & 0 \\ 0 & \delta_{i} & 0 & 0 \\ 0 & 0 & \delta_{i} & 0 \\ 0 & 0 & 0 & \delta_{i}\end{array}\right)\left(\begin{array}{cccc}f_{i}(t) & 0 & 0 & 0 \\ 0 & f_{i}(t) & 0 & 0 \\ 0 & 0 & f_{i}(t) & 0 \\ 0 & 0 & 0 & f_{i}(t)\end{array}\right)\left(\begin{array}{cccc}-\frac{R_{s n}}{L_{d}} & 0 & 0 & 0 \\ 0 & -\frac{R_{s n}}{L_{d}} & 0 & 0 \\ 0 & -\frac{3 n_{p} \psi_{f}}{2 J_{n}} & \frac{K_{o p t}}{J} \omega_{m i} & 0 \\ 0 & 0 & 0 & 0\end{array}\right)$

$\Delta B_{i}=0$

\subsection{MPP reference model}

In this part, we design a reference model that can specify the trajectory of the maximum power point (MPP). The considered model takes into account the optimal turbine speed calculated in real time from the wind speed, in order to subsequently provide the reference control law corresponding to the optimal operation. Therefore, it is necessary to orient the permanent flux in quadrature with the stator current generating the torque. This allows to an independent control between the flux and the electromagnetic torque.

Once the optimal rotor speed $\omega_{m o p t}=\frac{V_{w} \lambda_{\text {opt }}}{R}$ is calculated $\left\{\begin{array}{l}i_{\text {sdopt }}=0 \\ i_{\text {sqopt }}=\left(\frac{2 K_{0}}{3 n_{p} \psi_{f}}\right) \omega_{\text {mopt }}^{2}\end{array}\right.$

In this context, and based on the nonlinear model (12), the reference model to be designed is defined by the following equation:

$\dot{x}_{r}(t)=A_{r} x_{r}(t)+B_{r} u_{r}(t)$

Where

$$
\begin{aligned}
& A_{r}=\left(\begin{array}{cccc}
-\left(\frac{R_{s}}{L_{d}}+\frac{K_{i}}{L_{d}}\right) & n_{p} \omega_{m r} & 0 & 0 \\
-n_{p} \omega_{m r} & -\left(\frac{R_{s}}{L_{d}}+\frac{K_{i}}{L_{d}}\right) & -\frac{n_{p} \psi_{f}}{L_{d}} & 0 \\
0 & -\frac{3 n_{p} \psi_{f}}{2 J} & \frac{K_{0}}{J} \omega_{m r} & 0 \\
0 & 0 & -\frac{1}{R C}
\end{array}\right), \\
& x_{r}=\left(\begin{array}{c}
i_{s d r} \\
i_{s q r} \\
\omega_{m r} \\
u_{d c r}
\end{array}\right), B_{r}=\left(\begin{array}{cc}
\frac{1}{L_{d}} & 0 \\
0 & \frac{1}{L_{d}} \\
0 & 0 \\
\frac{3}{2 C}\left(\frac{i_{s d r}}{u_{d c r}}\right) & \frac{3}{2 C}\left(\frac{i_{s q r}}{u_{d c r}}\right)
\end{array}\right)
\end{aligned}
$$

$K_{i}$ is a positive parameters which allows to improve the dynamic of the closed-loop system and $u_{r}=\left(\begin{array}{ll}u_{s d r} & u_{s q r}\end{array}\right)^{T}$ represent the reference control law which defined as follows:

$\left\{\begin{array}{l}u_{\text {sdr }}=\left(R_{s}-K_{i}\right) i_{\text {sdopt }}+L_{d} n_{p} \omega_{\text {mopt }} i_{\text {sqopt }}+L_{d} \frac{d i_{\text {sdopt }}}{d t} \\ u_{\text {sqr }}=\left(R_{s}-K_{i}\right) i_{\text {sqopt }}-L_{d} n_{p} \omega_{m r} i_{\text {sdopt }}-n_{p} \omega_{\text {mopt }} \psi_{f}+L_{d} \frac{d i_{\text {sqopt }}}{d t}\end{array}\right.$

The reference model (24) is also nonlinear via the premise variable $z_{r 1}=\omega_{m r}, z_{r 2}=\left(\frac{i_{s d r}}{u_{d c r}}\right)$ and $z_{r 3}=\left(\frac{i_{s q r}}{u_{d c r}}\right)$. It can be 
described by the following rules

If $\left(z_{r 1}(t)\right.$ is $\left.F_{i k}\right)$ and $\left(z_{r 2}(t)\right.$ is $\left.F_{j k}\right)$ and $\left(z_{r 3}(t)\right.$ is $\left.F_{l k}\right)$

then $\dot{x}_{r i}(t)=A_{r i} x_{r}(t)+B_{r i} u_{r}(t), i=1,2, \cdots, 8$

The global TS fuzzy reference model is inferred as:

$\dot{x}_{r}(t)=\sum_{i=1}^{r} h_{i}\left(z_{r i}(t)\right)\left(A_{r i} x_{r}(t)+B_{r i} u_{r}(t)\right)$

\subsection{Fuzzy controller design}

The optimal operating condition of the WECS is achieved when the tracking error $e_{r}(t)=\left(x(t)-x_{r}(t)\right)$ converges to zero for all wind speed variations and uncertainly which affect the wind turbine parameters. Hence, the trajectory tracking problem is converted to a fuzzy state feedback control for which the proposed control law is given by [13, 14]:

$u(t)=\sum_{j=1}^{8} h_{j}(z(t)) K_{j}\left(x(t)-x_{r}(t)\right)$

Thus, taking into account the control law (28), the tracking dynamics error is defined as:

$\dot{e}_{r}(t)=\sum_{i=1}^{r} \sum_{j=1}^{r} h_{i}\left(z(t) h_{j}\left(z(t)\left(\begin{array}{l}\left(\left(A_{i}+\Delta A_{i}\right)+\left(B_{i}+\Delta B_{i}\right) K_{j}\right) e_{r}(t) \\ +\left(A_{i}-A_{r i}+\Delta A_{i}\right) x_{r}(t)-B_{r i} u_{r}(t)\end{array}\right)\right.\right.$

The dynamic errors equations (29) and the reference model equation (27) allow to an augmented state-space form as follows:

$$
\dot{\bar{x}}(t)=\sum_{i=1}^{r} \sum_{j=1}^{r} h_{i}(z(t)) h_{j}(z(t))\left(\bar{G}_{i j} \bar{x}(t)+\bar{B}_{r i} u_{r}(t)\right)
$$

where

$$
\begin{aligned}
& \bar{G}_{i j}=\bar{A}_{i j}+\Delta \bar{A}_{i j}=\left(\begin{array}{cc}
\left(A_{i}+B_{i} K_{j}\right) & \left(A_{i}-A_{r i}\right) \\
0 & A_{r i}
\end{array}\right)+\left(\begin{array}{cc}
\Delta A_{i}+\Delta B_{i} K_{j} & \Delta A_{i} \\
0 & 0
\end{array}\right) \\
& \bar{x}(t)=\left(\begin{array}{c}
e_{r}(t) \\
x_{r}(t)
\end{array}\right) \text { and } \bar{B}_{r i}=\left(\begin{array}{c}
-B_{r i} \\
B_{r i}
\end{array}\right)
\end{aligned}
$$

Additionally, to deal with the problem of the rapidly changing wind speed, the $\mathrm{H}_{\infty}$ performance related to the tracking error is introduced as follows [20, 21]:

$$
\int_{0}^{t_{f}}\left(\bar{x}(t)^{T} \bar{Q} \bar{x}(t)\right) \leq \rho^{2} \int_{0}^{t_{f}}\left(u_{r}(t)^{T} u_{r}(t)\right)
$$

Where $\bar{Q}=\left(\begin{array}{ll}Q & 0 \\ 0 & 0\end{array}\right), \rho$ is a defined value and $\mathrm{Q}$ is a positive definite weighting matrix.

Hence, the objective of this study is to determine a robust fuzzy controller (28) with the $\mathrm{H}_{\infty}$ tracking performance (31) able to force the (WECS) system to operate very close to its maximum power trajectory for all wind speed variations and parametric uncertainties. The main result is stated in the following theorem.
Theorem 1. Consider the TS uncertain system (21), the closed-loop system (30) is asymptotically stable and the $H_{\infty}$ performance (31) with the attenuation level $\rho$ is bounded, if there a symmetric definite positive matrices $X_{I}$, $P_{2}$, matrices $Y_{i}$ and the scalars $\varepsilon_{A i 1}, \varepsilon_{A i 2}, \varepsilon_{B i 1}$ satisfy the following optimization problem:

$$
\underset{\left(X_{1}, P_{2}\right)}{\min }(\rho)
$$

Subject to

$$
\left[\begin{array}{cccccc}
\Pi_{11} & E_{A i} X_{1} & E_{B i} Y_{j} & \left(A_{i}-A_{r i}\right) & -B_{i} & X_{1} \\
* & -\varepsilon_{A i 1}^{-1} & 0 & 0 & 0 & 0 \\
* & * & -\varepsilon_{B i 1}^{-1} & 0 & 0 & 0 \\
* & * & * & \Pi_{44} & P_{2} B_{r i} & 0 \\
* & * & * & * & -\rho^{2} I_{n} & 0 \\
* & * & * & * & * & -Q^{-1}
\end{array}\right]<0
$$

where

$$
\begin{aligned}
& \Pi_{11}=X_{1} A_{i}^{T}+A_{i} X_{1}+Y_{j}^{T} B_{i}^{T}+B_{i} Y_{j}+\left(\varepsilon_{A i 1}+\varepsilon_{A i 2}^{-1}\right) D_{A i} D_{A i}^{T}+\varepsilon_{B i 1} D_{B i} D_{B i}^{T} \\
& \Pi_{44}=A_{r i}^{T} P_{2}+P_{2} A_{r i}+\varepsilon_{A i 1} E_{A i} E_{A i}^{T} \text { and } K_{i}=Y_{i} X_{1}^{-1}
\end{aligned}
$$

\section{Proof:}

Let consider the following candidate quadratic Lyapunov function:

$$
V(\bar{x}(t))=\bar{x}^{T}(t) \bar{P} \bar{x}(t)
$$

where $\bar{P}=\operatorname{diag}\left(P_{1}, P_{2}\right)$, the attenuation of perturbation related to the tracking error is ensured when the following inequality is verify:

$$
\dot{V}(\bar{x}(t))+\bar{x}^{T}(t) \bar{P} \bar{x}(t)-\rho^{2} u_{r}^{T}(t) u_{r}(t)<0
$$

Taking into account the time-derivative of the function (33) along the closed-loop system (30), inequality (34) becomes:

$$
\sum_{i=1}^{8} \sum_{j=1}^{8} h_{i}(z(t)) h_{j}(z(t))\left[\begin{array}{c}
\bar{x}(t) \\
u_{r}(t)
\end{array}\right]^{T}\left[\begin{array}{cc}
\bar{G}_{i j}^{T} \bar{P}+\bar{P} \bar{G}_{i j}+\bar{Q} & \bar{P} \bar{B}_{r i} \\
\bar{B}_{r i}{ }^{T} \bar{P} & -\rho^{2} I
\end{array}\right]\left[\begin{array}{c}
\bar{x}(t) \\
u_{r}(t)
\end{array}\right]<0
$$

Equation (35) is satisfied if the following condition holds:

$\left[\begin{array}{cc}\bar{G}_{i j}^{T} \bar{P}+\bar{P} \bar{G}_{i j}+\bar{Q} & \bar{P} \bar{B}_{r i} \\ \bar{B}_{r i}{ }^{T} \bar{P} & -\rho^{2} I\end{array}\right]<0$

Note that inequality (36) can be rewritten as:

$\bar{\Upsilon}_{i j}+\Delta \bar{\Upsilon}_{i j}<0$

where

$$
\bar{\Upsilon}_{i j}=\left(\begin{array}{ccc}
h\left(P_{1}\left(A_{i}+B_{i} K_{j}\right)+Q\right. & P_{1}\left(A_{i}-A_{r i}\right)_{1} & -P_{1} B_{i} \\
* & A_{r i}^{T} P_{2}+P_{2} A_{r i} & P_{2} B_{r i} \\
* & * & -\rho^{2} I_{n}
\end{array}\right)
$$




$$
\Delta \bar{\Upsilon}_{i j}=\left(\begin{array}{ccc}
h\left(P_{1}\left(\Delta A_{i}+\Delta B_{i} K_{j}\right)\right. & P_{1} \Delta A_{i} & 0 \\
* & 0 & 0 \\
* & * & 0
\end{array}\right)
$$

Pre-and post multiply the BMI (37) by $\operatorname{diag}\left(X=P_{1}^{-1}, I, I, I\right)$, consider the variable change $Y_{j}=K_{j} X$ and using both the uncertainties structure defined in section 3.2 and the well known lemma $1, \Delta \bar{\Upsilon}_{i j}$ can be bounded as follows:

$$
\Delta \bar{\Upsilon}_{i j} \leq\left(\begin{array}{ccc}
\left(\begin{array}{c}
\left(\varepsilon_{A i 1}+\varepsilon_{A i 2}^{-1}\right) D_{A i} D_{A i}^{T}+\varepsilon_{B i 1} D_{B i} D_{B i}^{T} \\
+\varepsilon_{A i 1}^{-1} X E_{A i} E_{A i}^{T} X+\varepsilon_{B i 1}^{-1} Y_{j}^{T} E_{B i} E_{B i}^{T} Y_{j}
\end{array}\right) & 0 & 0 \\
0 & \varepsilon_{A i 2} E_{A i}^{T} E_{A i} & 0 \\
0 & 0 & 0
\end{array}\right)
$$

By using the condition (38) and applying the Schur complement, we get LMI (32).

\section{Numerical simulation}

In order to evaluate the performance of the proposed modelbased fuzzy tracking controller applied to the WECS, a variable wind speed profile is adopted as shown in Fig. 5a The specifications of the WECS are stated in the appendix A. We assume that the stator resistance $R_{s}$ and the inertia $J$ will undergo a variation of $30 \%$ from their nominal value at the time $t_{1}=20 \mathrm{~s}$ and $t_{1}=30 \mathrm{~s}$, respectively. The simulation tests included the analysis of tracking accuracy of MPP, and the study of the dynamic performance during the wind speed variation. The TS uncertain model (27) exactly represents the dynamic behavior of the nonlinear model (20) under the condition that the premise $z_{k}(t)$ are bounded as :

$z_{1 \min }=-0.05 \mathrm{~A} /, z_{1 \max }=0.5 \mathrm{~A} / \mathrm{V}, \quad z_{2 \min }=-0.05 \mathrm{~A} / \mathrm{V}, \quad z_{2 \max }=0.075 \mathrm{~A} / \mathrm{V}$, $\omega_{\min }=-200 r d / s$ and $\omega_{\max }=200 r d / s$.

By using the proposed controller, the turbine power response, the DC link voltage and the generator power tracking error are illustrated in Fig. 5. Fig. 5b show that, the power error between the output generator and output turbine is due essentially to the stator resistive losses which is proportional to the square of the $\mathrm{d}-\mathrm{q}$ stator current. In addition, Fig. 5c illustrate that the variation of the (WECS) parameters (Rs and $\mathrm{J}$ ) and the abrupt change of the wind speed, doesn't affect the performances of the proposed fuzzy controller, which allows to guarantee a low power tracking error which does not exceed $0.56 \%$ even we increase the stator resistance and the total inertia of $30 \%$ of theirs nominal values. This proves that the fuzzy controller forces the wind turbine to operate close to the optimal power trajectory which leads to an important transfer of the available wind power to the DC link side.
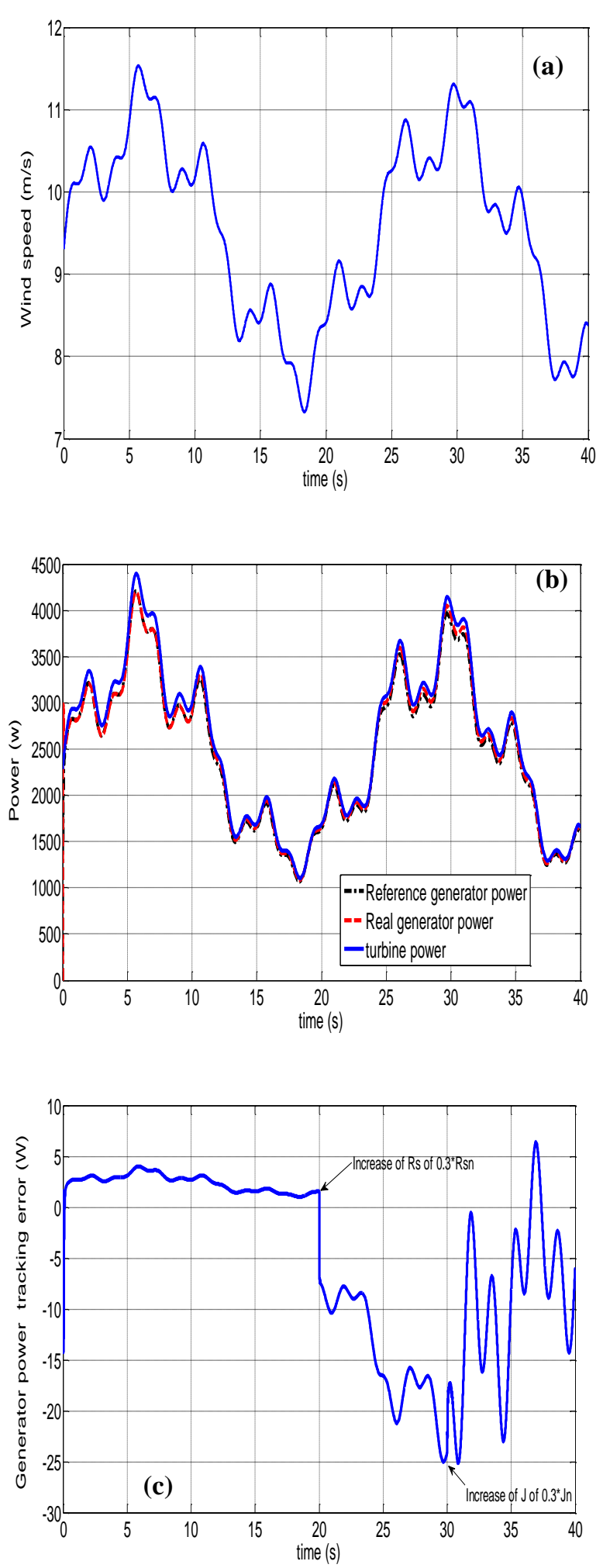

Fig. 5. (a) Profile of wind speed, (b) generator-turbine power and (c) generator power tracking error

Figure. 6a show that the real DC link voltage follows perfectly the reference trajectory delivered by the TS reference model. Moreover, for the same wind speed profile, a rapid convergence of the rotor speed towards the reference speed trajectory is illustrated in Fig. $6 \mathrm{~b}$ and consequently a good tracking optimal power accuracy is achieved. 

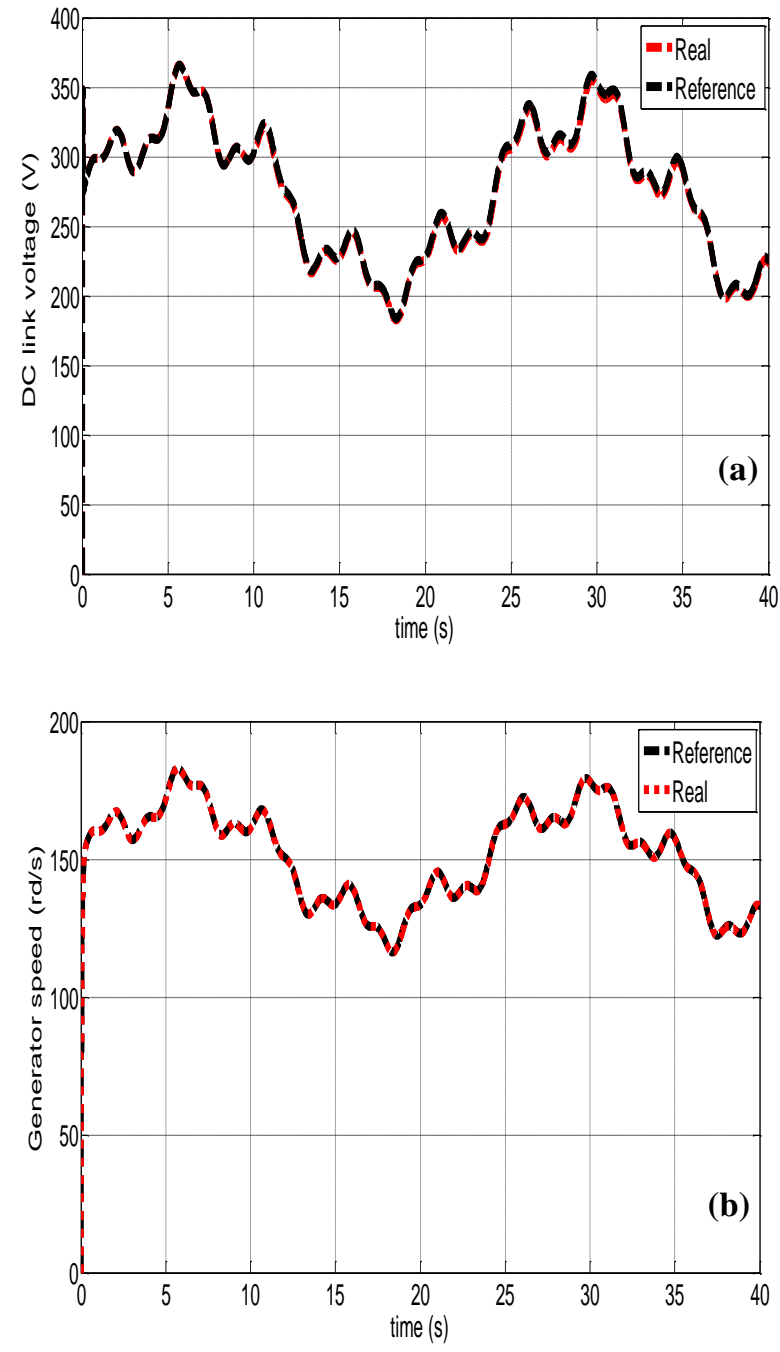

Fig . 6. (a) DC link voltage and (b) generator speed

As shows in Fig. 7a, the d-axis stator current is kept constant at zero, which proves that the decoupling control characteristic between the flux and the electromagnetic torque is obtained, despite of wind speed variation and the change of system parameters (specially $R_{s}$ and $J$ ).

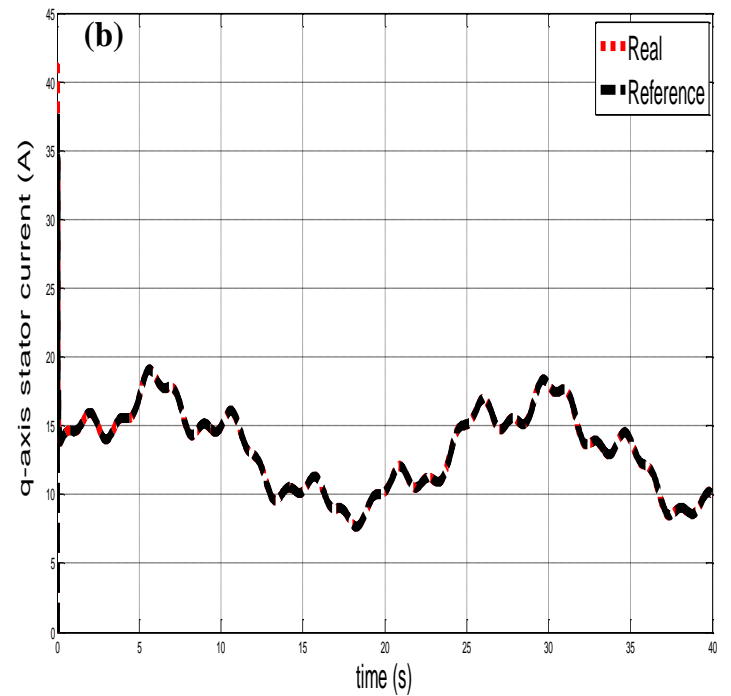

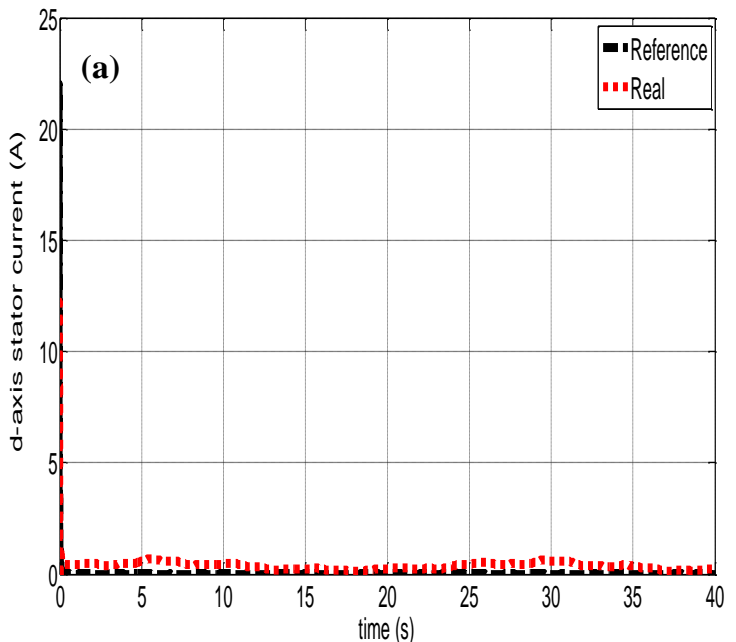

Fig . 7. (a) DC link voltage and (b) generator speed

\section{Conclusion}

This paper presented a robust reference model-based tracking controller of WECS system. The main advantage of this TS fuzzy strategy control is to ensure the extraction of maximum wind turbine power even of varying wind speed profile and parameters uncertainty. A TS reference model is designed to generate the optimal trajectory corresponding to the maximum power. Here, the stability problem is reformulated as a Linear Matrix Inequality using the $\mathrm{H} \infty$ performance. Finally simulation results are proposed to shown the effectiveness of the proposed fuzzy approach.

\section{Appendix . System parameters}

\section{A.1. Wind turbine parameters}

Air density $\rho=1.205 \mathrm{~kg} / \mathrm{m}^{3}$, rotor radius $R=1.74 \mathrm{~m}$, optimal tip speed ratio $\lambda_{\text {opt }}=6.9$, maximum power coefficient $C_{P_{\max }}=0.47$.

\section{A.2. PMSG parameters}

Rated power $6.4 \mathrm{~kW}$, pole pairs number $\mathrm{np}=4$, stator inductance $L d=L q=5.5 \mathrm{mH}$, stator resistance $R_{s}=0.57 \Omega$ and inertia $J=0.01645 \mathrm{~kg} \mathrm{~m} 2$.

\section{References}

[1] W. Leithead, S. de la Salle, and D. Readon, " Role and objectives for control of wind turbines", IEE Proceedings Part, vol. 138, pp. 135-148, 1991.

[2] A. Ghaffari, M. Krstic and S. Seshagiri, “ Power Optimization and Control in Wind Energy Conversion Systems Using Extremum Seeking “. IEEE transactions on control systems technology, Vol. 22, pp. 1668-1695, 2014. 
[3] S. P. Uma, S. Manikandan, " Control technique for variable speed wind turbine using PI controller ". IEEE International Conference on Emerging Trends in Computing, Communication and Nanotechnology 25-26 March 2013, India.

[4] M. EI Mokadem, V. Courtecuisse, C. Saudemont, B. Robyns, and J. Deuse, “ Fuzzy Logic Supervisor-Based Primary Frequency Control Experiments of a VariableSpeed Wind Generator ". IEEE Transaction on Power Systems, Vol. 24, No. 1, pp. 407-417, 2009.

[5] L. Krichen, B. Francois, and A. Ouali, " A fuzzy logic supervisor for active and reactive power control of a fixed speed wind energy conversion system ". Electric Power Systems Research, Vol. 78, No. 3, pp. 418-424, 2008.

[6] A. Medjber, A. Guessoum, H. Belmili and A. Mellit, "New neural network and fuzzy logic controllers to monitor maximum power for wind energy conversion system “, Energy, Vol. 106, pp. 137-146, 2016.

[7] T. Ekelund, "Modelling and linear quadratic optimal control of wind turbines ", $\mathrm{PhD}$ thesis, Chalmers University of Technology, 1997.

[8] I. Munteanu, N. Cutululis, A. Bratcu, E. Ceanga "Optimization of variable speed wind power systems based on a LQG approach", Control Engineering Practice, Vol. 13, pp. 903-912, 2005.

[9] R. B. Cardenas and M. Molinas, “ Optimal LQG Controller for Variable Speed Wind Turbine Based on Genetic Algorithms “. Energy Procedia, vol. 20, pp.207$216,2012$.

[10] H. Guo and Q. Guo " $\mathrm{H}_{\infty}$ Control of Adjustable-Pitch Wind Turbine Adjustable-Pitch System ", 5th International Power Electronics and Motion Control Conference. Shanghai, China, 2006.

[11] H. Moradi G. Vossoughi. " Robust control of the variable speed wind turbines in the presence of uncertainties: A comparison between $\mathrm{H}_{\infty}$ and PID controllers“. Energy, Vol 90, pp. 1508-1521, 2015.

[12] X. A. Mseddi, S. Le Ballois, H. Aloui and L. Vido, "Robust control of a HESG for a wind energy application “. Electric Power Systems Research, vol.168, pp.250-260, 2019.

[13] T. Takagi and M. Sugeno, "Fuzzy identification of system and its applications to modeling and control". IEEE Transactions on Systems, Man, and Cybernetics, vol 15, pp.116-132, 1985.

[14] A.M. Nagy, G. Mourot, B. Marx, G. Schutz, J. Ragot , "Model structure simplification of a biological reactor". 15th IFAC Symposium on System Identification (SYSID’09), 6-8 juillet 2009, Saint Malo, France.

[15] A.M. Nagy, G. Mourot, B. Marx, G. Schutz, J. Ragot , "Modélisation d'un réacteur biologique à l'aide d'une structure multimodèle. Méthode analytique d'obtention d'un multimodèle“, Journal Européen des Systèmes Automatisés, Vol. 44, pp. 423-443, 2010.
[16] C. S. Tseng, B. S. Chen, and , H. J. Uang, “ Fuzzy tracking control design for non linear dynamic system via TS fuzzy model “. IEEE Transactions on Fuzzy Systems, Vol 9, pp. 381-392, 2001.

[17] M. Allouche, K. Dahech, M. Chaabane and D. Mehdi, " Fuzzy observer-based control for maximum powerpoint tracking of a photovoltaic system ". International Journal of Systems Science, Vol 49, pp. 1061-1073, 2018.

[18] H. Moodi and D. Bustan, "Wind turbine control using T-S systems with nonlinear consequent parts ". Energy, vol. 172, pp. 922-931, 2019.

[19] Harrabi, M. Souissi, A. Aitouche and M. Chaabane, “ Intelligent Control of Wind Conversion System based on PMSG using T-S Fuzzy Scheme “, International Journal of Renewable Energy Research, Vol.5, pp. 952-960, 2015 .

[20] C. S. Chiu, Z. H .Li, and Y. H. Chen, “ T-S Fuzzy Direct Maximum Power Point Tracking of Wind Energy Conversion Systems “, International Journal of Fuzzy Systems, Vol. 15, pp. 192-202, 2013.

[21] C. S. Chiu, T. S. Chiang and Y. T. Lee, "Maximum Power Control of Wind Energy Conversation Systems via a T-S Fuzzy Model-based Approach “. International Conference on Fuzzy Systems, Barcelona, Spain, 2010.

[22] H. H. Benbouhenni, Z. Boudjema and A. Belaidi, “ Using Three-Level Fuzzy Space Vector Modulation Method to Improve Indirect Vector Control Strategy of a DFIG Based Wind Energy Conversion Systems“. International Journal of Smart Grid - ijSmartGrid, Vol 2, No 3, pp. 154-170, 2018.

[23] K. D. Mercado, J. Jiménez, M. Christian and G. Quintero, " Hybrid renewable energy system based on intelligent optimization techniques", International Conference on Renewable Energy Research and Applications (ICRERA), Birmingham, UK, 2016.

[24] M. Quraan, Q. Farhat, M. Bornat, "A new control scheme of back-to-back converter for wind energy technology“,San Diego, USA, 2017.

[25] S. P. Mishra and A. Kumar, "Application of brushless excitation system in Wind power generation",Palermo, Italy, 2015. 